\title{
A SCOPING REVIEW PROTOCOL TO MAP THE EVIDENCE ON SELF-REPORTED HEALTH AND NEUROTICISM IN OLDER ADULTS
}

\author{
Protocolo de revisão de escopo para mapear as evidências \\ sobre autopercepção de saúde e neuroticismo em idosos
}

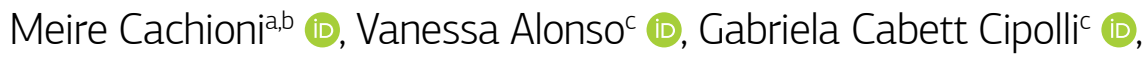 \\ Ruth Caldeira de Meloa (D), Constança Paúl ${ }^{b}$ (D)
}

OBJECTIVE: To identify the evidence on self-reported health and neuroticism in older adults. METHODS: Indexed literature published in English, Spanish and Portuguese will be systematically searched and retrieved from 10 databases; reference lists from included studies will be manually searched. Two authors will independently screen titles, abstracts, and full texts against the eligibility criteria. A customized data extraction form will be used to perform data extraction of the included studies, which will be: studies written in English, Portuguese, and Spanish; studies of older adults aged 55 years or over (mean age is 60 years at least); studies of community-dwelling older adults; studies that evaluated both self-reported health and personality; studies that evaluated self-reported health and personality with validated instruments; observational, review, and intervention studies. RESULTS: The results will be presented in a tabular format, accompanied by a narrative summary.

KEYWORDS: aged; personality; neuroticism; self-assessment.

OBJETIVO: Identificar as evidências sobre autopercepção de saúde e neuroticismo em idosos. METODOLOGIA: A literatura indexada publicada em inglês, espanhol e português será sistematicamente pesquisada e coletada em 10 bases de dados; as listas de referência dos estudos incluídos serão pesquisadas manualmente. Dois autores irão avaliar títulos, resumos e textos completos de forma independente de acordo com os critérios de elegibilidade. Um formulário de extração de dados customizado será utilizado para realizar a extração de dados dos estudos incluídos, que serão: estudos em inglês, português e espanhol; estudos com idosos com 55 anos ou mais (a média de idade é de 60 anos, no mínimo); estudos com idosos residentes na comunidade; estudos que avaliaram autopercepção de saúde e personalidade; estudos que avaliaram autopercepção de saúde e personalidade com instrumentos validados; estudos observacionais, de revisão e de intervenção. RESULTADOS: Os resultados serão apresentados em formato tabular, acompanhado de resumo narrativo.

PALAVRAS-CHAVE: idoso; personalidade; neuroticismo; autoavaliação.

aniversidade de São Paulo - São Paulo (SP), Brazil.

'Instituto de Ciências Biomédicas Abel Salazar, Centro de Investigação em Tecnologias e Serviços de Saúde, Universidade do Porto - Porto, Portugal. Universidade Estadual de Campinas - Campinas (SP), Brazil.

Correspondence data

Gabriela Cipolli - Universidade Estadual de Campinas - Rua Tessália Vieira de Camargo, 126 - Cidade Universitária Zeferino Vaz - CEP: 13083887 Campinas (SP), Brazil. E-mail: gabicipolli@hotmail.com @Gabicipolli

Received on: 11/7/2020. Accepted on: 1/24/2021

How to cite this article: Cachioni M, Alonso V, Cipolli G, Melo RC, Paúl C. A scoping review protocol to map the evidence on self-reported health and neuroticism in older adults. Geriatr Gerontol Aging. 2021;15:e0210007. https://doi.org/10.5327/Z2447-212320212000137

https://doi.org/10.5327/Z2447-212320212000137 


\section{INTRODUCTION}

"Personality" refers to individual differences in characteristic patterns of thought, feeling, and behavior. ${ }^{1}$ It is a construct that encompasses basic dispositions or trends, self-concept, typical adaptations, objective biography, and external influences, which allows to describe, explain, and predict behaviors. $^{2}$

The generalized hypothesis that personality affects health status is supported by increasing evidence in research evaluating self-reported health in various sociocultural contexts and age cohorts. People receive input about their physical health from both internal (e.g., body sensations) and external (e.g., health care professionals) sources. ${ }^{3}$ All those inputs are processed and cognitively organized and will affect how people assess their own health. ${ }^{3}$ In Jylhäs self-reported health model, ${ }^{4}$ individual psychological factors such as affective dispositions create an important structure for evaluating health components, resulting in an important influence on the assessment of the individual's health. The tendency to experience frequent positive or negative affect is strongly related to personality traits, especially extroversion and neuroticism. ${ }^{5,6}$

Personality traits are examples of characteristics associated with results in health evaluation. They are established predictors of health and longevity as strong as socioeconomic status and schooling. ${ }^{7-10}$ They are generally understood as lasting tendencies to feel, think, and behave in similar life situations. ${ }^{11}$ However, Chopik and Kitayama ${ }^{12}$ found that personality traits can be characterized by both stability and lifelong changes. The primary interpretation of age-related changes is that our personalities change in response to the roles and social responsibilities we adopt over time. ${ }^{12}$ Authors such as Letzring et al. ${ }^{13}$ suggest that changes in personality traits in adulthood are also associated with self-reported health changes.

Löckenhoff et al. ${ }^{14}$ suggested that there are at least two ways by which personality traits can influence subjective health assessment. First, personality can indirectly influence self-reported health through its action on objective health; personality traits can moderate physiological responses to stress or promote healthy or unhealthy behavior patterns. For example, neuroticism, which is the general tendency to experience different forms of negative affect, ${ }^{15}$ is probably associated with different health outcomes through physiological reactions to stress. ${ }^{16,17}$ Neuroticism is a predictor of many different mental and physical disorders including comorbidities and frequency of use of mental and general health services. ${ }^{18}$ However, healthy neuroticism can be good, especially when accompanied by higher conscientiousness. Conscientiousness may provide the bases of self-discipline and planning that are required to take actions; if neurotic people channel their concerns into proactive health behaviors, such as urgent search for medical care, this may substantially improve the prognosis of treatment. ${ }^{19,20}$

Although all five major personality traits (openness to experience, conscientiousness, extroversion, neuroticism, and kindness) are related to health in the literature, the two most consistent predictors of positive self-reported health, clinically evaluated biomarkers, and longevity are high conscientiousness and low neuroticism. ${ }^{21}$ There is evidence indicating that neuroticism, extroversion, and openness to experience tend to decline throughout life. A hypothesis is that this late decline coincides with a rapid decline in health and cognitive capacity. ${ }^{22}$ Low scores in conscientiousness and high scores in neuroticism indicate lower self-rated health. ${ }^{23}$ Reductions in conscientiousness and extroversion and increases in neuroticism predict worse self-reported physical health. ${ }^{24}$

The second way by which personality dimensions can influence self-reported health is shaping subjective interpretations about objective health status. ${ }^{14}$ Neuroticism is an important moderator of reported symptoms. People with a high level of neuroticism are more likely to report unfounded symptoms with no physiological basis to amplify their symptoms and bodily sensations and ask for medical help than those with a low level of neuroticism. ${ }^{25}$ They also show more negative interpretations of their health status and a lower level of self-reported health. ${ }^{26}$ This second path that prioritizes subjective interpretations of physical health suggests that individuals' views on their general lives probably also play a significant role in self-reported health. ${ }^{17}$

Authors such as Löckenhoff et al. ${ }^{27}$ and Letzring et al. ${ }^{13}$ suggest that there is a need for studies to examine the association of neuroticism and self-reported health in older adults, considering that this population has a wide range of health problems, even though their self-reports and perceptions are not always negative. Therefore, investigating a possible relationship between self-assessment of health and personality trait "neuroticism" among them is a matter of great importance for the formulation of public health policies. This review will identify evidence in the literature on the relationship between self-reported health and neuroticism in older adults.

\section{METHODS}

The present review will be conducted based on the Preferred Reporting Items for Systematic Reviews and Meta-Analysis Extension for Scoping Reviews (PRISMA-ScR) ${ }^{28}$ and previously published recommendations about scoping review methodology. ${ }^{29-33}$ As recommended, the present protocol was preregistered on the Open Science Framework (https://osf. 
io/jswp9). The main steps adopted for this scoping review are summarized in the following subsections.

\section{Identifying the research question}

The review questions for this scoping review are:

- Do personality traits influence self-reported health in community-dwelling older adults?;

- What is the relationship between neuroticism and self-reported health in community-dwelling older adults?

The population, concept, and context (PCC) framework recommended by the Joanna Briggs Institute for scoping reviews will be used in this review to determine the research question and eligibility criteria. ${ }^{30}$ Studies will be selected according to inclusion criteria. This review will consider studies that include community-dwelling older adults (55 years old or over), men and/or women (mean age 60 years at least) [participants].
This review will consider gerontological literature that reports neuroticism and self-reported health in older adults, including all synonyms for both terms [concept]. This review will consider published studies conducted in the community as long as they had included older adults [context].

\section{Identifying relevant studies}

This scoping review aims to identify published studies in English, Spanish, and Portuguese, with no date limits in searches. The search strategy designed for PubMed is detailed in Table 1. A second search strategy using all identified keywords and index terms will be done in all included databases, and their reference lists will be manually searched. The final search string will be applied in the following databases: Ageline, BVS-Bireme, CINAHL, Cochrane, Embase, PsycArticles, PSYCINFO, PubMed, Scopus, and Web of Science. The search process will be conducted with the support of a specialized librarian.

Table 1. PRISMA-P 2015 Checklist.

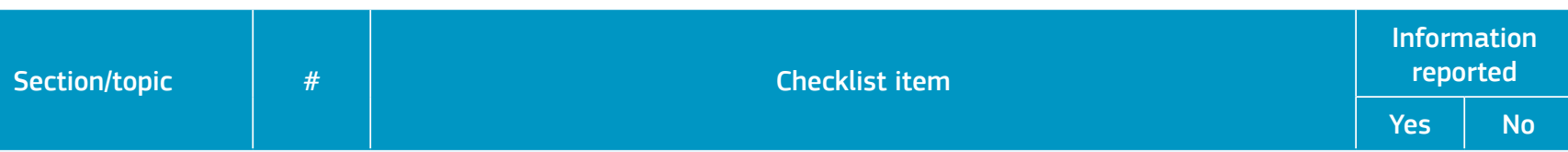

ADMINISTRATIVE INFORMATION

\begin{tabular}{|c|c|c|c|c|}
\hline Title & & & & \\
\hline Identification & $1 a$ & Identify the report as a protocol of a systematic review & 区 & $\square$ \\
\hline Update & $1 b$ & If the protocol is for an update of a previous systematic review, identify as such & $\square$ & $\square$ \\
\hline Registration & 2 & $\begin{array}{l}\text { If registered, provide the name of the registry (e.g., PROSPERO) and registration } \\
\text { number in the Abstract }\end{array}$ & 凶 & $\square$ \\
\hline \multicolumn{5}{|l|}{ Authors } \\
\hline Contact & $3 a$ & $\begin{array}{l}\text { Provide name, institutional affiliation, and e-mail address of all protocol authors; } \\
\text { provide physical mailing address of corresponding author }\end{array}$ & 凶 & $\square$ \\
\hline Contributions & $3 b$ & Describe contributions of protocol authors and identify the guarantor of the review & 凶 & $\square$ \\
\hline Amendments & 4 & $\begin{array}{l}\text { If the protocol represents an amendment of a previously completed or published } \\
\text { protocol, identify as such and list changes; otherwise, } \\
\text { state plan for documenting important protocol amendments }\end{array}$ & $\square$ & $\square$ \\
\hline \multicolumn{5}{|l|}{ Support } \\
\hline Sources & $5 a$ & Indicate sources of financial or other support for the review & 凶 & $\square$ \\
\hline Sponsor & $5 b$ & Provide name for the review funder and/or sponsor & $\square$ & $\square$ \\
\hline $\begin{array}{l}\text { Role of sponsor/ } \\
\text { funder }\end{array}$ & $5 c$ & $\begin{array}{l}\text { Describe roles of funder(s), sponsor(s), and/or institution(s), } \\
\text { if any, in developing the protocol }\end{array}$ & $\square$ & $\square$ \\
\hline \multicolumn{5}{|l|}{ INTRODUCTION } \\
\hline Rationale & 6 & Describe the rationale for the review in the context of what is already known & 凶 & $\square$ \\
\hline Objectives & 7 & $\begin{array}{l}\text { Provide an explicit statement of the question(s) the review will address with } \\
\text { reference to participants, interventions, comparators, and outcomes (PICO) }\end{array}$ & 凶 & $\square$ \\
\hline
\end{tabular}


Table 1. Continuation.

\begin{tabular}{l|l|l|l|l|} 
& \multicolumn{2}{|c|}{$\begin{array}{c}\text { Information } \\
\text { reported }\end{array}$} \\
\cline { 3 - 4 } Section/topic & Checklist item & Yes & No
\end{tabular}

METHODS

\begin{tabular}{|c|c|c|c|c|}
\hline Eligibility criteria & 8 & $\begin{array}{l}\text { Specify the study characteristics (e.g., PICO, study design, setting, time frame) } \\
\text { and report characteristics (e.g., years considered, language, publication status) to } \\
\text { be used as criteria for eligibility for the review }\end{array}$ & 凶 & $\square$ \\
\hline $\begin{array}{l}\text { Information } \\
\text { sources }\end{array}$ & 9 & $\begin{array}{c}\text { Describe all intended information sources (e.g., electronic databases, } \\
\text { contact with study authors, trial registers, or other grey literature sources) with } \\
\text { planned dates of coverage }\end{array}$ & 凶 & $\square$ \\
\hline Search strategy & 10 & $\begin{array}{l}\text { Present draft of search strategy to be used for at least one electronic database, } \\
\text { including planned limits, such that it could be repeated }\end{array}$ & 凶 & $\square$ \\
\hline
\end{tabular}

STUDY RECORDS

\begin{tabular}{|c|c|c|c|c|}
\hline $\begin{array}{l}\text { Data } \\
\text { management }\end{array}$ & $11 a$ & $\begin{array}{l}\text { Describe the mechanism(s) that will be used to manage records and data } \\
\text { throughout the review }\end{array}$ & 区 & $\square$ \\
\hline $\begin{array}{l}\text { Selection } \\
\text { process }\end{array}$ & $11 b$ & $\begin{array}{l}\text { State the process that will be used for selecting studies (e.g., two independent } \\
\text { reviewers) through each phase of the review (i.e., screening, eligibility, and } \\
\text { inclusion in meta-analysis) }\end{array}$ & 凶 & $\square$ \\
\hline $\begin{array}{l}\text { Data collection } \\
\text { process }\end{array}$ & $11 \mathrm{c}$ & $\begin{array}{l}\text { Describe planned method of extracting data from reports } \\
\text { (e.g., piloting forms, done independently, in duplicate), any processes for } \\
\text { obtaining and confirming data from investigators }\end{array}$ & 区 & $\square$ \\
\hline Data items & 12 & $\begin{array}{l}\text { List and define all variables for which data will be sought (e.g., PICO items, } \\
\text { funding sources), any pre-planned data assumptions and simplifications }\end{array}$ & 凶 & $\square$ \\
\hline $\begin{array}{l}\text { Outcomes and } \\
\text { prioritization }\end{array}$ & 13 & $\begin{array}{l}\text { List and define all outcomes for which data will be sought, including prioritization } \\
\text { of main and additional outcomes, with rationale }\end{array}$ & $\square$ & $\square$ \\
\hline $\begin{array}{l}\text { Risk of bias in } \\
\text { individual studies }\end{array}$ & 14 & $\begin{array}{c}\text { Describe anticipated methods for assessing risk of bias of individual studies, } \\
\text { including whether this will be done at the outcome or study level, or both; state } \\
\text { how this information will be used in data synthesis }\end{array}$ & $\square$ & $\square$ \\
\hline \multicolumn{5}{|l|}{ DATA } \\
\hline \multirow{4}{*}{ Synthesis } & $15 a$ & Describe criteria under which study data will be quantitatively synthesized & 凶 & $\square$ \\
\hline & $15 b$ & $\begin{array}{l}\text { If data are appropriate for quantitative synthesis, describe planned summary } \\
\text { measures, methods of handling data, and methods of combining data from } \\
\text { studies, including any planned exploration of consistency (e.g., } I^{2} \text {, Kendall's tau) }\end{array}$ & $\square$ & $\square$ \\
\hline & $15 c$ & $\begin{array}{l}\text { Describe any proposed additional analyses } \\
\text { (e.g., sensitivity or subgroup analyses, meta-regression) }\end{array}$ & $\square$ & $\square$ \\
\hline & $15 d$ & $\begin{array}{l}\text { If quantitative synthesis is not appropriate, describe } \\
\text { the type of summary planned }\end{array}$ & $\square$ & $\square$ \\
\hline Meta-bias(es) & 16 & $\begin{array}{c}\text { Specify any planned assessment of meta-bias(es) (e.g., publication bias across } \\
\text { studies, selective reporting within studies) }\end{array}$ & $\square$ & $\square$ \\
\hline $\begin{array}{l}\text { Confidence in } \\
\text { cumulative } \\
\text { evidence }\end{array}$ & 17 & $\begin{array}{l}\text { Describe how the strength of the body of evidence } \\
\text { will be assessed (e.g., GRADE) }\end{array}$ & $\square$ & $\square$ \\
\hline
\end{tabular}

Source: adapted for use with protocol submissions to Systematic Reviews from Table $3^{34}$. 


\section{Selecting the studies}

Two authors will select studies considering the inclusion criteria and using Rayyan (https://rayyan.qcri.org/welcome), a web and mobile app for systematic reviews, to analyze titles and abstracts of the articles. If they disagree, a third author will be consulted. Selected studies will be read in full by two authors, and discrepancies will be solved by consensus. The date of the studies that meet the eligibility criteria will be imported into the Endnote Web library database, and the reference lists of the selected studies will be reviewed. The inclusion criteria for the present review follows the PCC framework, which is recommended to guide scoping reviews. The following studies will be considered:

- studies of community-dwelling older adults (55 years old and over), men and/or women (mean age 60 years at least) [participants];

- gerontological literature that reports neuroticism and self-reported health in older adults [context];

- published studies conducted in the community as long as they had included older adults [concept].

- Studies using different research designs (observational studies, experimental studies, quantitative studies, and reviews) will be considered in the present scoping review. Papers will be excluded if they are:

- not fully published in the selected languages described above;

- grey literature (i.e., books, thesis, dissertations);

- case reports, letters to the editor, qualitative studies, case-control studies, commentaries, or opinion papers.

\section{Charting the data}

Relevant data for this review will be extracted from the included studies by two independent reviewers using methods recommended by Peters et al. ${ }^{29}$ Data extraction will include author(s), year of publication, article title, source (journal, volume, issue, page numbers), type of study, aims, sample size, population characteristics (mean age, sex, specific diseases), methods, instruments (neuroticism and self-reported health), level of neuroticism and self-reported health, and outcomes (https://osf.io/jswp9). Analysis of the selected articles will check whether the study methodology was robust, which statistical analyses were used for inference about self-reported health and neuroticism in older adults, and whether validated instruments were used to validate self-reported health and neuroticism.

Collating, summarizing, and reporting the results

The review decision process will be presented in a flow chart, including search results, removal of duplicate citations, phases of study selection (title/abstract and full text), reasons for excluding papers after full text screening, and final number of included studies. To illustrate this process, a PRISMA flow diagram will be used. The results will be presented in a tabular format, accompanied by a narrative summary related to the objective of the present scoping review. A data presentation table will be developed based on the extracted data, which will be grouped together according to study type.

\section{Ethical approval}

Since the scoping review methodology aims to synthesize information from available publications, this study does not require ethical approval.

\section{Relevance and dissemination}

This scoping review has potential to inform health care researchers about how neuroticism might be able to affect self-reported health in many ways. Results from this review may assist the formulation of public health policies, which can improve the quality of life of older adults. The complete scoping review will be disseminated through presentations at aging conferences and publication in a peer-reviewed international journal.

\section{ACKNOWLEDGMENTS}

The authors gratefully acknowledge the contribution of Ana Paula Morais e Oliveira, a librarian at the Universidade Estadual de Campinas (Brazil), for her specialized support during the search process.

\section{CONFLICTS OF INTEREST}

The authors declare no conflict of interest.

\section{FUNDING}

This research did not receive any specific grant from funding agencies in the public, commercial, or not-forprofit sectors.

\section{AUTHORS' CONTRIBUTION}

MC: conceptualization, writing - review \& editing. VA: conceptualization, writing - review \& editing. GCC: conceptualization, writing - review \& editing. RCM: writing - review \& editing. CP: writing — review \& editing. 


\section{REFERENCES}

1. Roberts BW, Mroczek D. Personality Trait Change in Adulthood. Curr Dir Psychol Sci. 2008;17(1):31-5. https://doi.org/10.1111\%2Fj.14678721.2008.00543.x

2. Costa PT Jr, McCrae RR. Stability and change in personality from adolescence through adulthood: The developing structure of temperament and personality from infancy to adulthood. New York: Lawrence Erlbaum Associate; 1994.

3. Williams PG, Wasserman MS, Lotto AJ. Individual differences in self-assessed health: an information-processing investigation of health and illness cognition. Health Psychol. 2003;22(1):3-11

4. Jylhä M. What is self-rated health and why does it predict mortality? Towards a unified conceptual model. Soc Sci Med. 2009;69(3):30716. https://doi.org/10.1016/j.socscimed.2009.05.013

5. Allik J, Realo A. Emotional experience and its relation to the fivefactor model in Estonian. J Pers. 1997;65(3):625-47. https://doi. org/10.1111/j.1467-6494.1997.tb00329.x

6. Costa PT Jr, McCrae RR. Influence of extraversion and neuroticism on subjective well-being: happy and unhappy people. J Pers Soc Psychol. 1980;38(4):668-78. https://doi.org/10.1037//0022-3514.38.4.668

7. Roberts BW, Kuncel NR, Shiner R, Caspi A, Goldberg LR. The Power of Personality: The Comparative Validity of Personality Traits, Socioeconomic Status, and Cognitive Ability for Predicting Important Life Outcomes. Perspect Psychol Sci. 2007;2(4):313-45. https://doi. org/10.1111\%2Fj.1745-6916.2007.00047.x

8. Deary IJ, Weiss A, Batty GD. Intelligence and Personality as Predictors of Illness and Death: How Researchers in Differential Psychology and Chronic Disease Epidemiology Are Collaborating to Understand and Address Health Inequalities. Psychol Sci Public Interest. 2010;1 (2):53-79. https://doi.org/10.1177/1529100610387081

9. Ferguson E. Personality is of central concern to understand health: towards a theoretical model for health psychology. Health Psychol Rev. 2013;7(Suppl. 1):S32-S70. https://dx.doi.org/10.108 0\%2F17437199.2010.547985

10. Weston SJ, Hill PL, Jackson JJ. Personality traits predict the onset of disease. Soc Psychol Personal Sci. 2015;6(3):309-17.

11. Allik J, McCrae RR. A Five-Factor Theory perspective: The five-factor model of personality across cultures. New York: Kluwer Academic/ Plenum; 2002

12. Chopik WJ, Kitayama S. Personality change across the life span: Insights from a cross-cultural, longitudinal study. J Pers. 2018;86(3):508-21. https://doi.org/10.1111\%2Fjopy.12332

13. Letzring TD, Edmonds GW, Hampson SE. Personality Change at Mid-Life is Associated with Changes in Self-Rated Health: Evidence from the Hawaii Personality and Health Cohort. Pers Individ Dif. 2014;58:10.1016. https://dx.doi.org/10.1016\%2Fj.paid.2013.10.002

14. Löckenhoff CE, Sutin AR, Ferrucci L, Costa PT Jr. Personality traits and subjective health in the later years: The association between NEO-PI-R and SF-36 in advanced age is influenced by health status. J Res Pers. 2008;42(5):1334-46. https://doi.org/10.1016/j. jrp.2008.05.006

15. Costa PT Jr, McCrae RR. Revised NEO Personality Inventory (NEO-PI-R) and NEO Five-Factor Inventory (NEO- FFI) professional manual. Odessa: Psychological Assessment Resources; 1992.

16. Friedman HS, Kern ML. Personality, well-being, and health. Annu Rev Psychol. 2014;65:719-42. https://doi.org/10.1146/annurevpsych-010213-115123

17. Kööts-Ausmees L, Schmidt M, Esko T, Metspalu A, Allik J, Realo A. The Role of the Five-factor Personality Traits in General Self-rated Health. Eur J Pers. 2016;30(5):492-504. https://doi.org/10.1002/per.2058
18. Lahey BB. Public health significance of neuroticism. Am Psychol. 2009;64(4):241-56. https://dx.doi.org/10.1037\%2Fa0015309

19. Friedman HS. Long-term relations of personality and health: dynamisms, mechanisms, tropisms. J Pers. 2000;68(6):1089-107. https://doi.org/10.1111/1467-6494.00127

20. Turiano NA, Mroczek DK, Moynihan J, Chapman BP. Big 5 personality traits and interleukin-6: evidence for "healthy Neuroticism" in a US population sample. Brain Behav Immun. 2013;28:83-9. https://doi. org/10.1016/j.bbi.2012.10.020

21. Chapman B, Duberstein P, Lyness JM. Personality traits, education, and health-related quality of life among older adult primary care patients. J Gerontol B Psychol Sci Soc Sci. 2007;62(6):P343-52. https://doi.org/10.1093/geronb/62.6.p343

22. Wagner J, Ram N, Smith J, Gerstorf D. Personality trait development at the end of life: Antecedents and correlates of mean-level trajectories. J Pers Soc Psychol. 2016;111(3):411-29. https://doi.org/10.1037/ pspp0000071

23. Human LJ, Biesanz JC, Miller GE, Chen E, Lachman ME, Seeman TE. Is change bad? Personality change is associated with poorer psychological health and greater metabolic syndrome in midlife. Pers. 2013;81(3):249-60. https://dx.doi.org/10.1111\%2Fjopy.12002

24. Magee CA, Heaven PC, Miller LM. Personality change predicts selfreported mental and physical health. J Pers. 2013;81(3):324-34. https://doi.org/10.1111/j.1467-6494.2012.00802.x

25. Aiken-Morgan AT, Bichsel J, Savla J, Edwards CL, Whitfield KE. Associations between self-rated health and personality. Ethn Dis. 2014;24(4):418-22

26. Benyamini Y, Idler EL, Leventhal H, Leventhal EA. Positive affect and function as influences on self-assessments of health: expanding our view beyond illness and disability. J Gerontol B Psychol Sci Soc Sci. 2000;55(2):P107-16. https://doi.org/10.1093/geronb/55.2.p107

27. Löckenhoff CE, Terracciano A, Ferrucci L, Costa PT Jr. Five-factor personality traits and age trajectories of self-rated health: the role of question framing. J Pers. 2012;80(2):375-401. https://dx.doi. org/10.1111\%2Fj.1467-6494.2011.00724.x

28. Tricco AC, Lillie E, Zarin W, O'Brien KK, Colquhon H, Levac D, et al. PRISMA Extension for Scoping Reviews (PRISMA-ScR): Checklist and Explanation. Ann Intern Med. 2018;169(7):467-73. https://doi. org/10.7326/m18-0850

29. Peters MDJ, Godfrey CM, Khalil H, Mclnerney P, Parker D, Soares CB. Guidance for conducting systematic scoping reviews. Int J Evid Based Health. 2015;13(3):141-6. https://doi.org/10.1097/ xeb.0000000000000050

30. JBI Global Wiki. JBI Reviewer's Manual. JBI Global Wiki. Available at: https://reviewersmanual.joannabriggs.org/. Accessed in Oct, 2020

31. Arksey H, O'Malley L. Scoping studies: towards a methodological framework. Int J Soc Res Methodol. 2005;8(1):19-32. https://doi. org/10.1080/1364557032000119616

32. Levac D, Colquhoun H, O'Brien KK. Scoping studies: advancing the methodology. Implement Sci. 2010;5:69. https://doi.org/10.1186/17485908-5-69

33. Colquhoun HL, Levac D, O'Brien KK, Straus S, Tricco AC, Perrier $L$, et al. Scoping reviews: time for clarity in definition, methods, and reporting. J Clin Epidemiol. 2014;67(12):1291-4. https://doi. org/10.1016/j.jclinepi.2014.03.013

34. Moher D, Shamseer L, Clarke M, Ghersi D, Liberati A, Petticrew M, et al. Preferred reporting items for systematic review and metaanalysis protocols (PRISMA-P) 2015 statement. Syst Rev. 2015;4. https://doi.org/10.1186/2046-4053-4-1 